\title{
Performance Evaluation of Cascaded H-bridge Multilevel Grid-Connected Converter with Model Predictive Control Technique
}

\author{
Mohammad Ali Hosseinzadeh ${ }^{1}$, Maryam Sarbanzadeh ${ }^{1}$, Ali Salehi ${ }^{2}$, Marco Rivera $^{1}$ \\ Javier Munoz ${ }^{1}$, Patrick Wheeler ${ }^{3}$ \\ ${ }^{1}$ Faculty of Engineering, University of Talca, Curico, Chile \\ m.a_hosseinzadeh@yahoo.com; maryam_sarbanzadeh@yahoo.com; marcoriv@utalca.cl; jamunoz@utalca.cl \\ ${ }^{2}$ Faculty of Engineering, University of Sirjan, Sirjan, Iran \\ alisalehi282@yahoo.com \\ ${ }^{3}$ Faculty of Engineering, University of Nottingham, Nottingham, UK \\ pat.wheeler@nottingham.ac.uk
}

\begin{abstract}
Cascaded H-bridge multilevel converter (CHB) is a promising topology for grid-connection systems. On the other side, model predictive controls are advanced control strategies which have many advantages for power converters applications like as fast dynamic response and easy implementation. This paper proposes a model predictive current control for a singlephase cascaded H-bridge converter topology in two modes: symmetrical and asymmetrical in the grid-connection state. The performance principle of an $\mathrm{H}$-bridge converter and its cascaded connection are analyzed. Then, the mathematical model and predictive current control are explained in a grid-connected condition. The performance of the $\mathrm{CHB}$ topologies with the proposed predictive current control technique is evaluated by the simulation results in different conditions.
\end{abstract}

Index Terms - cascaded H-bridge; multi-level converters; mathematical model; model predictive control.

\section{INTRODUCTION}

Multi-level converters/inverters are more important topologies than conventional two-level converter in power electronic applications. A multilevel converter is an electrical device that generates a stepped waveform by many DC sources located in the input [1]. The DC sources can be a photovoltaic or solar system, fuel cell, capacitors, etc. Generally, multilevel converters are separated into three groups: diode-clamped also called neutral point clamped (NPC), flying capacitor (FC) and cascaded H-bridge (CHB) converter [2], [3].

Each of these converters have advantages and disadvantages. The advantage of a diode-clamped converter is the use of the diode. In an NPC converter the DC-link voltage is generated to the same level by the combination of input capacitors, diode clamped and switching states. FC converter topology is similar to NPC topology with the difference that in a FC converter is used the flying capacitor instead of diode clamped to keep on the switching elements [4]-[6].

The CHB multilevel converter is formed by series connection of H-bridge cells each one with its own isolated DC sources. CHB multilevel converter can work in symmetrical or asymmetrical modes [7]. In the symmetric configuration, all DC sources are equal in magnitude, given a good modularity to the topology. Asymmetric configurations are used in order to increase the number of output voltage levels by selecting different DC source values [8].

On the other hand, the CHB converter is a popular topology that is used in industrial applications. The main important thing in the CHB is the current control. Research and simulation results in predictive current control in the literature show that predictive control method plays an irreplaceable role in solving the problem of large current distortion in classical converters [9], [10].

A predictive control method uses the model of the system to predict the behavior of system variables to the time horizon and cost function as a criterion for the proper separation of functions. A simplified approach that can be used for the modulation of the converter is a system with a limited number of states [11], [12].

All switching states are evaluated online in the predictive control method, then one of the states that minimize the cost function is selected. Several major advantages have led to the introduction of a predictive control for handling power electronics components, one of these advantages is its simplicity and easy understanding to be used in a wide range of power converters.

The predictive control method for the use of voltage source converters requires high computational volume. But nowadays, fast microprocessors are able to do by using a reconfiguration control and implement it in such a converter. When predictive control is implemented in a real power system, the calculation time should be considered [11]-[13].

In this paper, a model predictive control strategy is presented for a single phase cascaded $\mathrm{H}$ bridge converter by considering two cases: symmetric and asymmetric configurations in a grid connected system. The mathematical model of the CHB converter, load model and predictive current control technique 
are derived and explained. Finally, the simulation results for a symmetrical and asymmetrical CHB converter are presented to confirm the proposed predictive current control strategy.

\section{H-BRIDGE CONVERTER}

An H-bridge converter consists of four power switches and a DC voltage source, Fig.1 indicates the power topology of an H-bridge converter. The type of switches are unidirectional and includes an insulated gate bipolar transistor (IGBT) and a parallel diode. Table I gives the switching states of an $\mathrm{H}-$ bridge converter. This topology generates three voltage levels of $-V_{d c},+V_{d c}$ and 0 .

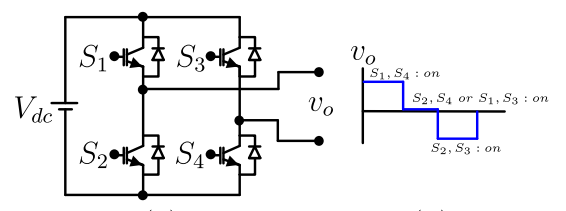

(a)

(b)

Fig. 1: a) H-bridge converter topology; b) output waveform

TABLE I: Output voltage of H-bridge converter

\begin{tabular}{ccccc}
\hline $\mathbf{V}_{o}$ & $\mathbf{S}_{1}$ & $\mathbf{S}_{2}$ & $\mathbf{S}_{3}$ & $\mathbf{S}_{4}$ \\
\hline \hline$+V_{d c}$ & 1 & 0 & 0 & 1 \\
0 & 1 & 0 & 1 & 0 \\
0 & 0 & 1 & 0 & 1 \\
$-V_{d c}$ & 0 & 1 & 1 & 0 \\
\hline \hline
\end{tabular}

\section{CASCADED H-BRIDGe CONVERTER}

Fig. 2 displays a single-phase cascaded converter topology which consists of $n \mathrm{H}$-bridge. If the magnitudes of DC sources are chosen similar, this configuration is called symmetrical. Therefore, the total number of voltage levels is as follows:

$$
N_{L}=2 n+1
$$

If the magnitudes of input DC supplies are chosen differently, this topology is called asymmetrical and each H-bridge generates three different voltage levels. Therefore, the total number of voltage levels are dependent on the magnitude of DC sources. There are two methods for determination of DC supplies in a CHB converter. The first method is binary $(1: 2: 4)$, in this case, the number of levels is as follows:

$$
N_{L}=2^{n+1}-1
$$

The second method is trinary (1:3:9). The number of level for this case is calculated as follows:

$$
N_{L}=3^{n}
$$

In this paper, a cascaded H-bridge converter consists of three cascaded units which is investigated in two modes: symmetrical and asymmetrical.

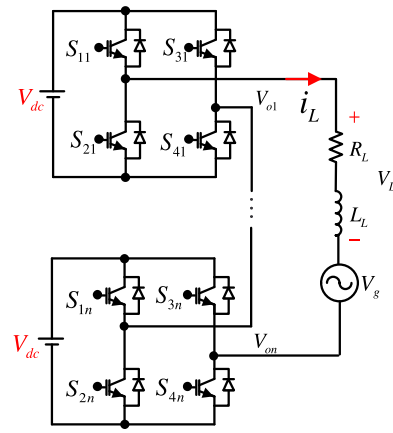

(a)

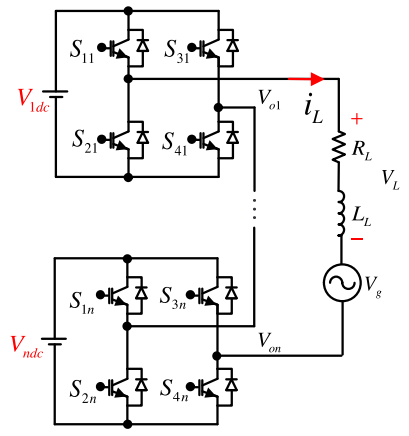

(b)
Fig. 2: CHB grid-connected converters: a) symmetrical topology; b) asymmetrical topology.

\section{A. 7-level Symmetrical CHB Converter}

In this section, a 7-level symmetrical CHB converter is analyzed. As mentioned in section II, in the symmetrical topology, the magnitudes of all DC sources have same values. The output voltage is the sum of the output voltage of each $\mathrm{H}$ bridge. This topology consists of three series H-bridge that it can generate 7-level at the output (according to equation (2)). All switching states and the output voltage of 7-level CHB are shown in Table II, III. A CHB converter with three cascaded H-bridge converter has 64 switching states.

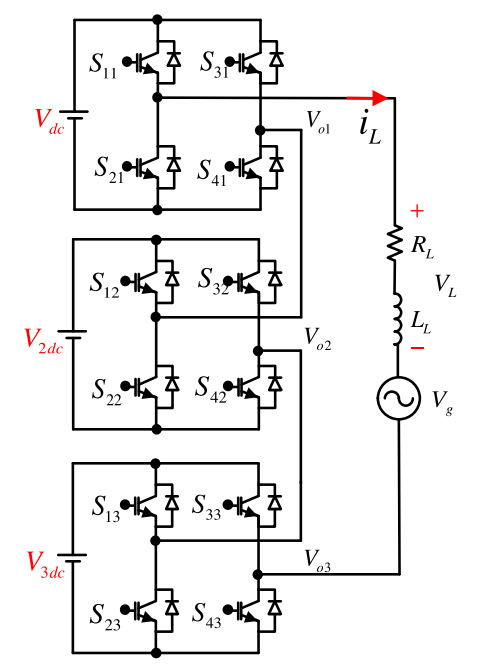

Fig. 3: H-bridge converter with three series units.

\section{B. 15-level and 27-level Asymmetrical CHB Converters}

In this section, two asymmetrical $\mathrm{CHB}$ converters are analyzed. As mentioned section II, in the asymmetrical CHB, the values of all DC sources have binary and trinary values. This arrangement consists of three series H-bridge that it can generate 15-level and 27-level at the output according to equation (2) and (3).

\section{Predictive Current Control}

Generally, there are three conventional strategies in order to control and modulate a CHB converter: pulse width modulation (PWM) based on carrier, space vector modulation 
TABLE II: All Possible Switching States of a Cascaded H-bridge converter

\begin{tabular}{c|cccc|cccc|cccc}
\hline States & $\mathbf{S}_{11}$ & $\mathbf{S}_{21}$ & $\mathbf{S}_{31}$ & $\mathbf{S}_{41}$ & $\mathbf{S}_{12}$ & $\mathbf{S}_{22}$ & $\mathbf{S}_{32}$ & $\mathbf{S}_{42}$ & $\mathbf{S}_{13}$ & $\mathbf{S}_{23}$ & $\mathbf{S}_{33}$ & $\mathbf{S}_{43}$ \\
\hline \hline 1 & 1 & 0 & 1 & 0 & 1 & 0 & 1 & 0 & 1 & 0 & 1 & 0 \\
2 & 1 & 0 & 1 & 0 & 1 & 0 & 1 & 0 & 0 & 1 & 0 & 1 \\
3 & 1 & 0 & 1 & 0 & 0 & 1 & 0 & 1 & 1 & 0 & 1 & 0 \\
4 & 1 & 0 & 1 & 0 & 0 & 1 & 0 & 1 & 0 & 1 & 0 & 1 \\
5 & 0 & 1 & 0 & 1 & 1 & 0 & 0 & 1 & 1 & 0 & 1 & 0 \\
6 & 0 & 1 & 0 & 1 & 1 & 0 & 0 & 1 & 0 & 1 & 0 & 1 \\
7 & 0 & 1 & 0 & 1 & 0 & 1 & 0 & 1 & 1 & 0 & 1 & 0 \\
8 & 0 & 1 & 0 & 1 & 0 & 1 & 0 & 1 & 0 & 1 & 0 & 1 \\
9 & 1 & 0 & 0 & 1 & 1 & 0 & 1 & 0 & 0 & 1 & 1 & 0 \\
10 & 1 & 0 & 0 & 1 & 0 & 1 & 1 & 0 & 1 & 0 & 1 & 0 \\
11 & 1 & 0 & 1 & 0 & 1 & 0 & 0 & 1 & 0 & 1 & 1 & 0 \\
12 & 1 & 0 & 1 & 0 & 0 & 1 & 1 & 0 & 1 & 0 & 0 & 1 \\
13 & 0 & 1 & 1 & 0 & 1 & 0 & 0 & 1 & 1 & 0 & 1 & 1 \\
14 & 0 & 1 & 1 & 0 & 1 & 0 & 0 & 1 & 0 & 1 & 0 & 1 \\
15 & 0 & 1 & 1 & 0 & 1 & 0 & 1 & 0 & 1 & 0 & 0 & 1 \\
16 & 0 & 1 & 1 & 0 & 1 & 0 & 1 & 0 & 1 & 0 & 0 & 1 \\
17 & 0 & 1 & 1 & 0 & 0 & 1 & 0 & 1 & 1 & 0 & 0 & 1 \\
18 & 0 & 1 & 0 & 1 & 1 & 0 & 0 & 1 & 0 & 1 & 1 & 0 \\
19 & 0 & 1 & 0 & 1 & 0 & 1 & 1 & 0 & 1 & 0 & 0 & 1 \\
20 & 0 & 1 & 0 & 1 & 0 & 1 & 1 & 0 & 1 & 0 & 1 & 0 \\
21 & 0 & 1 & 0 & 1 & 0 & 1 & 1 & 0 & 0 & 1 & 0 & 1 \\
22 & 1 & 0 & 0 & 1 & 0 & 1 & 0 & 1 & 0 & 1 & 1 & 0 \\
23 & 1 & 0 & 0 & 1 & 1 & 0 & 0 & 1 & 0 & 1 & 1 & 0 \\
24 & 1 & 0 & 0 & 1 & 1 & 0 & 1 & 0 & 1 & 0 & 1 & 0 \\
25 & 1 & 0 & 0 & 1 & 1 & 0 & 1 & 0 & 0 & 1 & 0 & 1 \\
26 & 1 & 0 & 0 & 1 & 0 & 1 & 1 & 0 & 1 & 0 & 0 & 1 \\
27 & 1 & 0 & 1 & 0 & 1 & 0 & 0 & 1 & 1 & 0 & 1 & 0 \\
28 & 1 & 0 & 1 & 0 & 1 & 0 & 0 & 1 & 0 & 1 & 0 & 1 \\
29 & 1 & 0 & 1 & 0 & 1 & 0 & 1 & 0 & 1 & 0 & 0 & 1 \\
30 & 0 & 1 & 1 & 0 & 1 & 0 & 0 & 1 & 1 & 0 & 0 & 1 \\
31 & 0 & 1 & 0 & 1 & 1 & 0 & 0 & 1 & 0 & 1 & 0 & 1 \\
32 & 0 & 1 & 0 & 1 & 1 & 0 & 0 & 1 & 1 & 0 & 1 & 0 \\
33 & 0 & 1 & 0 & 1 & 0 & 1 & 0 & 1 & 1 & 0 & 0 & 1 \\
34 & 0 & 1 & 0 & 1 & 1 & 0 & 1 & 0 & 1 & 0 & 0 & 1 \\
35 & 1 & 0 & 0 & 1 & 0 & 1 & 0 & 1 & 1 & 0 & 1 & 0 \\
36 & 1 & 0 & 0 & 1 & 0 & 1 & 0 & 1 & 0 & 1 & 0 & 1 \\
37 & 1 & 0 & 1 & 0 & 0 & 1 & 0 & 1 & 1 & 0 & 0 & 1 \\
\hline \hline & & & & & & & & & & & & \\
\hline
\end{tabular}

(SVM) and fundamental switching strategy and advanced model predictive control [9], [10].

In this paper, the model predictive control strategy is applied to both states of symmetric and asymmetric CHB topologies. The predictive control method in the voltage source converter works based on all possible switching states of the converter. Based on the switching states of the converters the behavior of the controlled variables is predicted for all switching states. After, a cost function is defined in order to apply for each switching state. Then each switching state is chosen by the minimization of the cost function. Finally, in a predictive current control that applies to the VSC need three important steps as follows:

1- Cost function: to choose the best switching states among all switching states of CHB converter, the cost function is defined and minimized based on the error between the predictive currents (the cost function evaluates the error between the reference and the prediction) and the reference currents.

2- Converters model: to extract all possible switching states of the voltage source converter, the converter is modeled based on the output voltage vectors and the switching states.

3- Load model: to predict the variables of the system such as current, voltage and powers, the load is modeled based on the output voltage of the converter.

The block diagram of the predictive control applied to the current control for the CHB converter is displayed in Fig. 3.

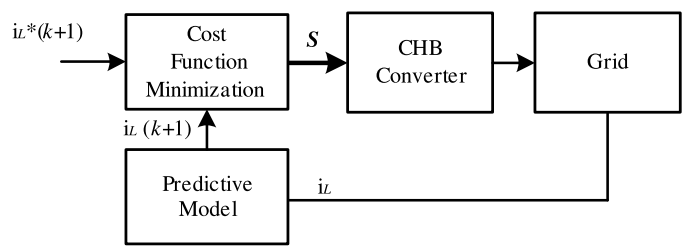

Fig. 4: Block diagram of model predictive current control for CHB converter.

\section{A. Mathematical Model of Cascaded H-bridge Multilevel Converter}

In a CHB converter, the output voltage of each cell is calculated as the voltage difference of switches in each cell. Then, each cell is controlled with two independent switching function and output voltage levels in each cell $v_{o j}$ calculated as:

$$
V_{o j}=V_{d c}\left(S_{1 j}-S_{3 j}\right)
$$


TABLE III: Switching States of 15-Level Cascaded H-bridge Converter

\begin{tabular}{c|cccc|cccc|cccc}
\hline States & $\mathbf{S}_{11}$ & $\mathbf{S}_{21}$ & $\mathbf{S}_{31}$ & $\mathbf{S}_{41}$ & $\mathbf{S}_{12}$ & $\mathbf{S}_{22}$ & $\mathbf{S}_{32}$ & $\mathbf{S}_{42}$ & $\mathbf{S}_{13}$ & $\mathbf{S}_{23}$ & $\mathbf{S}_{33}$ & $\mathbf{S}_{43}$ \\
\hline \hline 38 & 1 & 0 & 0 & 1 & 0 & 1 & 1 & 0 & 0 & 1 & 1 & 0 \\
39 & 1 & 0 & 1 & 0 & 1 & 0 & 1 & 0 & 0 & 1 & 1 & 0 \\
40 & 1 & 0 & 1 & 0 & 0 & 1 & 1 & 0 & 1 & 0 & 1 & 0 \\
41 & 1 & 0 & 1 & 0 & 0 & 1 & 1 & 0 & 0 & 1 & 0 & 1 \\
42 & 0 & 1 & 1 & 0 & 1 & 0 & 0 & 1 & 0 & 1 & 1 & 0 \\
43 & 1 & 0 & 0 & 1 & 1 & 0 & 1 & 0 & 1 & 0 & 1 & 0 \\
44 & 0 & 1 & 1 & 0 & 1 & 0 & 1 & 0 & 0 & 1 & 0 & 1 \\
45 & 0 & 1 & 1 & 0 & 0 & 1 & 1 & 0 & 1 & 0 & 0 & 1 \\
46 & 0 & 1 & 1 & 0 & 0 & 1 & 0 & 1 & 1 & 0 & 1 & 0 \\
47 & 0 & 1 & 0 & 1 & 1 & 0 & 1 & 0 & 0 & 1 & 1 & 0 \\
48 & 0 & 1 & 0 & 1 & 0 & 1 & 0 & 1 & 0 & 1 & 1 & 0 \\
49 & 1 & 0 & 1 & 0 & 0 & 1 & 0 & 1 & 0 & 1 & 1 & 0 \\
50 & 0 & 1 & 1 & 0 & 0 & 1 & 0 & 1 & 1 & 0 & 1 & 0 \\
51 & 1 & 0 & 0 & 1 & 1 & 0 & 0 & 1 & 1 & 0 & 1 & 0 \\
52 & 1 & 0 & 0 & 1 & 1 & 0 & 0 & 1 & 0 & 1 & 0 & 1 \\
53 & 1 & 0 & 0 & 1 & 1 & 0 & 1 & 0 & 1 & 0 & 0 & 1 \\
54 & 1 & 0 & 1 & 0 & 1 & 0 & 0 & 1 & 1 & 0 & 0 & 1 \\
55 & 0 & 1 & 0 & 1 & 1 & 0 & 0 & 1 & 1 & 0 & 0 & 1 \\
56 & 1 & 0 & 0 & 1 & 0 & 1 & 0 & 1 & 1 & 0 & 0 & 1 \\
57 & 1 & 0 & 1 & 0 & 0 & 1 & 1 & 0 & 0 & 1 & 1 & 0 \\
58 & 0 & 1 & 1 & 0 & 1 & 0 & 1 & 0 & 0 & 1 & 1 & 0 \\
59 & 0 & 1 & 1 & 0 & 0 & 1 & 1 & 0 & 1 & 0 & 1 & 0 \\
60 & 0 & 1 & 1 & 0 & 0 & 1 & 1 & 0 & 0 & 1 & 0 & 1 \\
61 & 0 & 1 & 1 & 0 & 0 & 1 & 0 & 1 & 0 & 1 & 1 & 0 \\
62 & 0 & 1 & 0 & 1 & 0 & 1 & 1 & 0 & 0 & 1 & 1 & 0 \\
63 & 1 & 0 & 0 & 1 & 0 & 0 & 0 & 1 & 1 & 0 & 0 & 1 \\
64 & 0 & 1 & 1 & 0 & 0 & 1 & 1 & 0 & 0 & 1 & 1 & 0 \\
\hline \hline
\end{tabular}

where $S_{1 j}$ and $S_{3 j}$ are the switching functions and $V_{d c}$ is DC source of each H-bridge. Let $S_{j}$ be a switching functions where $j=1,2, \cdots, n$. $S_{j}$ is defined by

$$
S_{j}=\left\{\begin{array}{l}
1: \text { if } S_{j} \text { are } O N \\
0: \text { if } S_{j} \text { are } O F F
\end{array}\right.
$$

For a symmetric configuration, the total output voltage in an CHB converter is obtained as follows:

$$
V_{o i}=V_{d c} \sum_{j=1}^{n}\left(S_{1 j}-S_{3 j}\right)
$$

And for an asymmetric configuration is:

$$
V_{o i}=\sum_{j=1}^{n}\left(S_{1 j}-S_{3 j}\right) V_{j d c}
$$

Also, the output current for symmetric and asymmetric topologies is as follows:

$$
i_{o j}=\left(S_{1 j} S_{3 j}\right) I_{L}
$$

where $i_{L}$ is the line current. Then,

$$
\begin{gathered}
V_{L}=R i_{L}+L \frac{d i_{L}}{d t} \\
V_{L}=V_{o 1}+V_{o 2}+V_{o 3} \\
i_{L}=i_{o 1}+i_{o 2}+i_{o 3}
\end{gathered}
$$

So, considering equation (6), the total output voltage for a 7-level symmetric CHB converter is obtained as follows:

$$
\left\{\begin{array}{l}
V_{o 1}=\left(S_{11}-S_{31}\right) V_{d c} \\
V_{o 2}=\left(S_{12}-S_{32}\right) V_{d c} \\
V_{o 3}=\left(S_{13}-S_{33}\right) V_{d c}
\end{array}\right.
$$

And for 15-level and 27-level asymmetric CHB converter are obtained as follows:

$$
\left\{\begin{array}{l}
V_{o 1}=\left(S_{11}-S_{31}\right) V_{1 d c} \\
V_{o 2}=\left(S_{12}-S_{32}\right) V_{2 d c} \\
V_{o 3}=\left(S_{13}-S_{33}\right) V_{3 d c}
\end{array}\right.
$$

So, the differentiation equation of line current in a 7-level symmetric topology is:

$\frac{d i_{L}}{d t}=\frac{R i_{L}+V_{d c}\left(\left(S_{11}+S_{12}+S_{13}\right)-\left(S_{31}+S_{32}+S_{33}\right)\right)}{L_{L}}$

For 15-level and 27-level asymmetric topologies are:

$\frac{d i_{L}}{d t}=\frac{R i_{L}+V_{d c}\left(\left(S_{11}+2 S_{12}+4 S_{13}\right)-\left(S_{31}+2 S_{32}+4 S_{33}\right)\right)}{L_{L}}$

$\frac{d i_{L}}{d t}=\frac{R i_{L}+V_{d c}\left(\left(S_{11}+3 S_{12}+9 S_{13}\right)-\left(S_{31}+3 S_{32}+9 S_{33}\right)\right)}{L_{L}}$

\section{B. Discrete-Time Model}

The discrete form of the load current of the converter for sampling time $T_{s}$ can be used to predict the current by measuring the voltage and load current at $k$. 


$$
\frac{d i_{L}}{d t} \simeq \frac{i_{L}(k+1)-i_{L}(k)}{T_{s}}
$$

By replacing in the system equations, the current-load equation is obtained as follows:

$$
\left.i_{L}(k+1)=\left(1-\frac{R T_{s}}{L}\right) i_{L}(k)+\frac{T_{s}}{L}\left(V_{L}(k)-V_{g}\right)\right)
$$

The cost function of the predictive control for a current control objective will take the form:

$$
g=\left|i_{L}(k)-i_{L}^{*}(k)\right|
$$

The cost function is calculated for CHB cascaded topology to correspond to all possible switching states that they are $4^{n}$ switching states. Here, $n$ is the number of cascaded units.

\section{Simulation Results}

In this section, the simulation results of the CHB converter are carried out under MATLAB/Simulink software in two case studies in the grid-connection state. In the first, the simulation results are presented for a 7-level symmetric CHB converter by proposed model predictive control and second case study is for 15-level and 27-level asymmetric CHB converters. All parameters in the simulation study are given in Table IV.

TABLE IV: System Parameters

\begin{tabular}{ccc}
\hline Variable & Parameters & Values \\
\hline \hline$V_{D C}$ & DC link voltage & $450 \mathrm{~V}$ \\
$C_{i n}$ & DC Capacitors & $1000 \mu \mathrm{F}$ \\
$R_{L}$ & Line Resistive & $10 \Omega$ \\
$L_{L}$ & Line Inductance & $10 \mathrm{mH}$ \\
$V_{g}$ & Grid Voltage & $220 \mathrm{~V}$ \\
$T_{s}$ & Sampling Time & $5 \mu \mathrm{s}$ \\
\hline \hline
\end{tabular}

\section{A. 7-Level Symmetric CHB Converter}

The structure of this converter is displayed in Fig. 3 and it has three H-bridge converters. DC capacitor's voltage corresponds to the symmetric method and all their values are same to each other and they are considered $V_{C, 1}=V_{C, 2}=V_{C, 3}=$ $150 \mathrm{~V}$. This structure creates 7-level with the peak of $450 \mathrm{~V}$ at the output.

The simulation results of 7-level CHB converter in gridtied condition is shown in Fig. 5. The grid voltage, the output voltage of 7-level CHB, grid current and THD's magnitude are presented in the simulation. As can see the output voltage symmetric CHB converter by proposed predictive current control technique is generated based on the required grid current. To validate the proposed current control a variation occurs in reference current in $t>0.15$ that the proposed control method tracks the reference current and generates 7level voltage by CHB converter very fast. The THD amplitude of grid current has a low amplitude of $0.03 \%$.
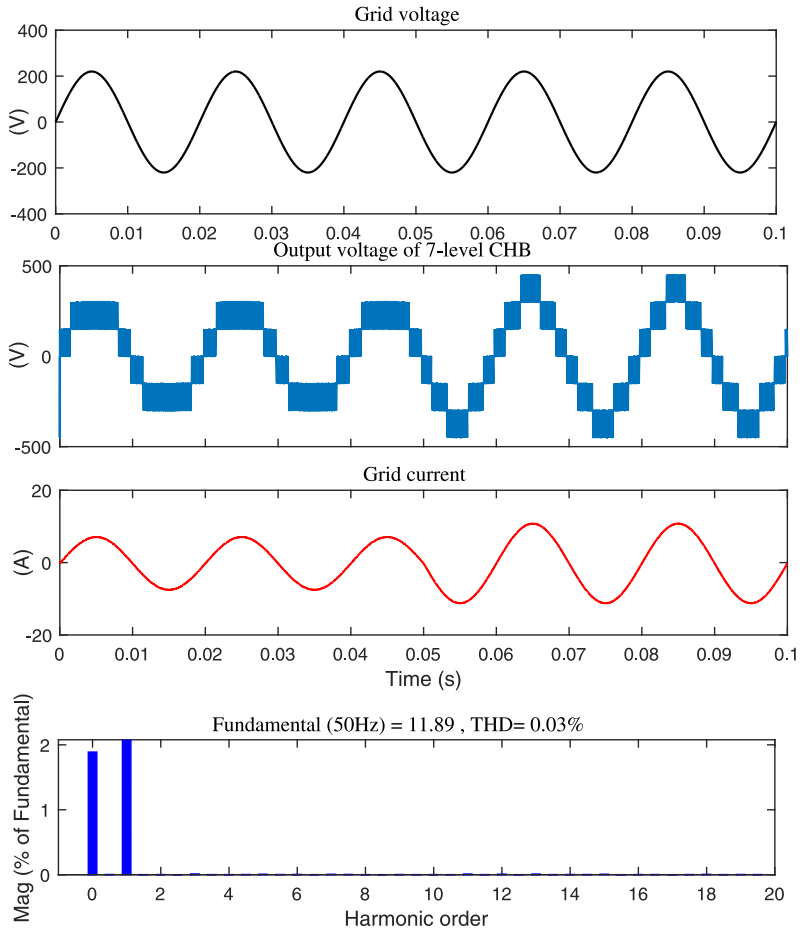

Fig. 5: Simulation results of grid-connected symmetric 7-level converter.

\section{B. 15-Level And 27-level Asymmetric CHB Converter}

The structure of this converter is same with symmetric topology and it consists of three H-bridge converters. DC sources values correspond to binary and trinary $(1: 2: 4)$ and (1:3:9) methods and they have values: $V_{C, 1}=50 \mathrm{~V}, V_{C, 2}=$ $150 \mathrm{~V}, V_{C, 3}=200 \mathrm{~V}$ for binary and $V_{C, 1}=30 \mathrm{~V}, V_{C, 2}=90 \mathrm{~V}$, $V_{C, 3}=270 \mathrm{~V}$ for trinary. These structures create 15-level and 27-level with the peaks of $400 \mathrm{~V}$ and $390 \mathrm{~V}$ at the output, respectively. The simulation results of 15-level and 27-level CHB converters in grid-tied condition is shown in Fig. 6. The grid voltage, output voltage of 7-level and 15-level CHB converters, grid current and THD's magnitudes have presented in this simulation. As can see the output voltage asymmetric CHB converters by proposed predictive current control technique are generated correspond to required grid current.

To validate the proposed current control a variation occurs in reference current in $t>0.15$ that the proposed control method tracks the reference current and generates 15-level and 27-level voltage by CHB converter very fast. The THD's amplitude of grid current is a very low amplitude of $0.01 \%$ for 15 -level CHB converter and zero for 27-level CHB converter.

\section{CONCLUSION}

This paper investigates asymmetric and two asymmetric CHB converter topologies in grid-connection condition by model predictive control. The CHB converter was consist of three cascaded H-bridge and three DC sources. The symmetric topology generated 7-level and asymmetric topologies based on a binary algorithm (1:2:4) generated 15-levels and base on a trinary algorithm (1:3:9) generated 27-level. The mathematical 

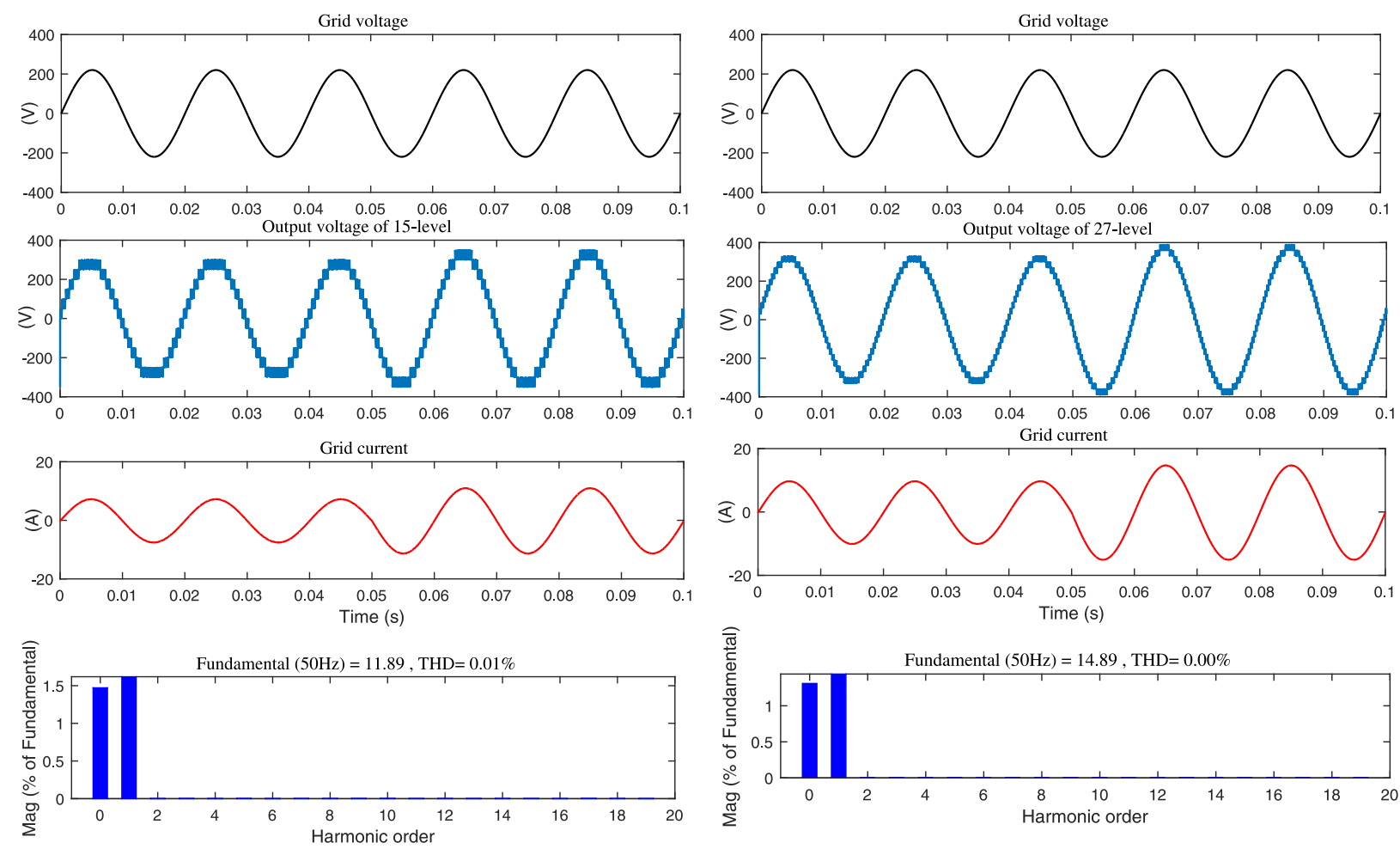

Fig. 6: Simulation results of grid-connected asymmetric 15-level and 27-level CHB converters.

model for a CHB converter and symmetric and asymmetric cascaded topologies were presented. To grid current control a model predictive control technique was applied. To validate the performance of CHB converter based on model predictive control the simulation were presented for 7, 15, 27-level CHB converter and the results were obtained as follows:

1- All output voltage of CHB converter topologies $(7,15$, 27-levels) were generated by model predictive control.

1- The dynamic response of the grid current was evaluated by a variation and the model predictive current control, control the current very fast.

3- The THD's amplitude for 7-level was $0.03 \%$, for 15 level was $0.01 \%$ and for $27-$ level it has a zero value that it reconfirms the model predictive control to control the CHB converter especially for reducing THD's amplitude.

\section{ACKNOWLEDGMENT}

The authors wish to acknowledge the financial support of FONDECYT Regular 1160690 Research Project.

\section{REFERENCES}

[1] S. Amamra, K. Meghriche, A. Cherifi and B. Francois, "Multilevel Inverter Topology for Renewable Energy Grid Integration," in IEEE Transactions on Industrial Electronics, vol. 64, no. 11, pp. 8855-8866, Nov. 2017.

[2] N. Sandeep, R.Y. Udaykumar, "Design and implementation of active neutral-point-clamped nine-level reduced device count inverter: an application to grid integrated renewable energy sources," IET Power Electron., vol. 11, no. 1, pp. 82-91, Feb. 2018.

[3] A. Abdelhakim, P. Mattavelli, G. Spiazzi, "A Very high resolution stacked multilevel inverter topology for adjustable speed drives," IEEE Trans. Ind. Electron., vol. 65, no. 3, pp. 2049-2056, Mar. 2018
[4] N. Arun, M.M. Noel, "Crisscross switched multilevel inverter using cascaded semi-half-bridge cells," IET Power Electron., vol. 11, no. 1, pp. 23-32, Feb. 2018.

[5] K. Gupta, A. Ranjan, P. Bhatnagar, L. Sahu, and S. Jain, "Multilevel inverter topologies with reduced device count: A review," IEEE Trans. Power Electron., vol. 31, no. 1, pp. 135-151, Jan. 2016.

[6] A.K. Sadigh, V. Dargahi, K. Corzine, "New flying-capacitor-based multilevel converter with optimized number of switches and capacitors for renewable energy integration," IEEE Trans. Energy Conversion., vol. 31, no. 3, pp. 846-859, Sept. 2016.

[7] E. Babaei, M.F Kangarlu, M.A. Hosseinzadeh, "Asymmetrical multilevel converter topology with reduced number of components," IET Power Electron., vol. 6, no. 6, pp. 11881196, Jan. 2013.

[8] S. S. Lee, M. Sidorov, C. S. Lim, N. R. N. Idris and Y. E. Heng, "Hybrid Cascaded Multilevel Inverter (HCMLI) With Improved Symmetrical 4Level Submodule," in IEEE Transactions on Power Electronics, vol. 33, no. 2, pp. 932-935, Feb. 2018.

[9] N. Susheela, P. S. Kumar and S. K. Sharma, "Generalized Algorithm of Reverse Mapping Based SVPWM Strategy for Diode-Clamped Multilevel Inverters," in IEEE Transactions on Industry Applications, vol. 54, no. 3, pp. 2425-2437, May-June 2018.

[10] B. H. Kumar and M. M. Lokhande, "Analysis of PWM techniques on multilevel cascaded H-Bridge three phase inverter," 2017 Recent Developments in Control, Automation and Power Engineering (RDCAPE), Noida, 2017, pp. 465-470.

[11] S. Vazquez, J. Rodriguez, M. Rivera, L. G. Franquelo and M. Norambuena, "Model Predictive Control for Power Converters and Drives: Advances and Trends," in IEEE Transactions on Industrial Electronics, vol. 64, no. 2, pp. 935-947, Feb. 2017.

[12] S. C. Ferreira, R. B. Gonzatti, R. R. Pereira, C. H. da Silva, L. E. B. da Silva and G. Lambert-Torres, "Finite Control Set Model Predictive Control for Dynamic Reactive Power Compensation With Hybrid Active Power Filters," in IEEE Transactions on Industrial Electronics, vol. 65, no. 3, pp. 2608-2617, March 2018

[13] R. Baidya, R. P. Aguilera, P. Acua, S. Vazquez and H. d. T. Mouton, "Multistep Model Predictive Control for Cascaded H-Bridge Inverters: Formulation and Analysis," in IEEE Transactions on Power Electronics, vol. 33, no. 1, pp. 876-886, Jan. 2018. 